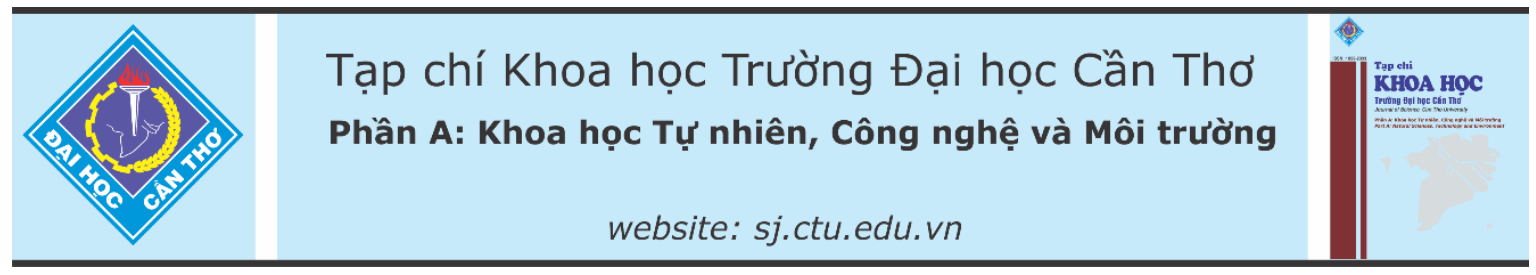

DOI:10.22144/ctu.jvn.2021.009

\title{
NGHIÊN CÚU KHẢ NĂNG GẮN KẾT VỚI ROTIGOTINE CỦA CLUSTER VÀNG Au, BẦNG LÝ THUYẾT PHIẾM HÀM MậT Độ
}

\author{
Phạm Vũ Nhật ${ }^{*}$, Nguyễn Thanh $\mathrm{Si}^{1}$, Nguyễn Thị Hòa ${ }^{1}$, Nguyễn Thị Yến Nhi ${ }^{2}$, \\ Trần Thị Ngọc Thảo ${ }^{1}$, Phạm Thị Bích Thảo ${ }^{1}$ và Nguyễn Thành Tiên ${ }^{1}$ \\ ${ }^{1}$ Khoa Khoa hoc Tự nhiên, Truò̀ng Đại học Cần Tho \\ ${ }^{2}$ Bộ môn Hóa họ, Khoa Khoa học Co bản, Truòng Đại học Kỹ thuật - Công nghệ Cần Tho \\ *Nguoòi chịu trách nhiệm về bài viết: PhạmVũ Nhật (email: nhat@ctu.edu.vn)
}

\section{Thông tin chung:}

Ngày nhận bài: 20/08/2020

Ngày nhận bài sủa: $28 / 10 / 2020$

Ngày duyệt đăng: 27/03/2021

Title:

A DFT study of Rotigotine binding to Au cluster

\section{Tù khóa:}

Cluster vàng, cysteine, lý thuyết DFT, rotigotine

\section{Keywords:}

Cysteine, DFT calculations, gold cluster, rotigotine

\begin{abstract}
Density functional theory (DFT) was employed to clarify the adsorption/desorption behaviors of the rotigotine (ROT) drug on the gold surface using the small Au6 gold cluster as a model reactant. Geometries of resulting complexes are optimized using the PBE functional in conjunction with the cc-pVTZ-PP basis set for gold and the cc-pVTZ basis set for the non-metals. The binding sites and energies, along with several quantum chemical indicators are also investigated at the same level of theory. Computed results show that the drug molecules tend to anchor on the gold cluster at the $N$ atom with binding energies around -18.6 $\mathrm{kcal} / \mathrm{mol}$ (in vacuum) and $-18.9 \mathrm{kcal} / \mathrm{mol}$ (in aqueous solution). If a visible light with a wavenumber of $v \approx 700 \mathrm{~nm}$ is applied, the time for the recovery of Au from the complex will be around 0.1 to 0.2 seconds at 298 $K$. In addition, the gold cluster is found to benefit from a larger change of energy gap that could be converted to an electrical signal for selective detection of ROT. Noticeably, the interaction between the drug and gold cluster is a reversible process and a drug release mechanism was also proposed. Accordingly, the drug is able to separate from the gold surface due to either a slight change of pH in tumor cells, or a presence of cysteine residues in protein matrices.
\end{abstract}

\section{TÓM TĂT}

Lý thuyết phiếm hàm mật độ (DFT) được sủ dụng để khảo sát co chế hấp phu phân tủ rotigotine (ROT) lên bề mặt vàng, sủ dụng cluster vàng Au làm mô hình phản ứng. Cấu trúc của các phức hợp sinh ra được tối uu hóa bởi phiếm hàm PBE kết hợp với bộ cơ sở cc-pVTZ-PP cho Au và ccpVTZ cho các phi kim. Vị trí, năng luợng liên kết và một số chỉ số luợng tử cũng được khảo sát tại cùng múc lý thuyết. Kết quả tính toán cho thấy các phân tử thuốc có xu hướng neo đậu trên cluster vàng thông qua nguyên tủ $N$ với năng luợng liên kết khoảng $-18,6 \mathrm{kcal} / \mathrm{mol}$ trong pha khi và $-18,9$ kcal/mol trong nuớc. Khi sủ dụng ánh sáng khả kiến với buớc sóng $v=$ $700 \mathrm{~nm}$, thời gian hồi phuc của Au, tù 0,1 đến 0,2 giây ở $298 \mathrm{~K}$. Ngoài ra, năng luợng vùng cấm của Au6 giảm đáng kể trong các phức hơp Au6 ROT và có thể được chuyển hóa thành tín hiệu điện giúp phát hiện chọn lọc ROT. Đáng luu ý, tuơng tác giũa ROT và cluster vàng là quá trình thuận nghịch, và co chế giải phóng ROT cũng đã được đề xuất. Theo đó, ROT dễ dàng tách khỏi bề mặt vàng do sự thay đổi nhỏ của pH trong tế bào khối u hoạc sụ hiện diện của du luợng cysteine trong các protein. 


\section{GIỚI THIẸU}

Gần đây, các cluster kim loại quí là chủ đề của vô số nghiên cứu xuất phát từ tính chất quang học vô cùng độc đáo của chúng (Fenwick et al., 2016; Xavier et al., 2012). Chúng được xem là những chất huỳnh quang (fluorophore) cao cấp so với các thuốc nhuộm hữu cơ hiện tại, đồng thời nhỏ hơn và ít độc hơn các chấm lượng tử (Choi et al., 2012; Gwinn et al., 2015; Obliosca et al., 2013). Các cluster kim loại quí có khả năng tương thích sinh học tốt, có ái lực khá mạnh với nhiều phân tử sinh học khác nhau, và tương đối dễ tổng hợp (Chah et al., 2005; Jain et al., 2006; Wang et al., 2005) nên rất thích hợp cho các ứng dụng trong phát triển các thiết bị dò tìm, cảm biến sinh học và những ứng dụng khác trong y học (Mani et al., 2009; Thaxton et al., 2006). Với các ứng dụng trên, trước hết chúng ta cần làm sáng tỏ cơ chể tương tác và các tính chất lý hóa liên quan. Nhiều kỹ thuật thực nghiệm đã được sử dụng để khảo sát kích thước và cấu trúc của hạt, hình thái bề mặt và sự tồn tại cấu trúc dạng keo. Các phương pháp sử dụng kính hiển vi như kính hiển vi điện tử truyền qua (transmission electron microscopy), kính hiển vi điện tử quét (scanning electron microscopy) và kính hiển vi lực nguyên tử (atomic force microscopy) có thể được sử dụng để đo kích thước hạt cũng như sự phân bố kích thước, hình dạng và hình thái bề mặt (Veronese \& Pasut, 2005). Kích thước hạt cũng có thể được quan sát bằng cách sử dụng các kỹ thuật tán xạ ánh sáng như nhiễu xạ laser (laser diffraction) và tán xạ ánh sáng động (dynamic light scattering) (Brar \& Verma, 2011). Phổ UV-Vis cũng đã được sử dụng để xác nhận sự hiện diện của liên kết disulfide (Kam et al., 2005), theo dõi vùng chuyển dịch điện tích từ kim loại sang phối tử (Achar \& Puddephatt, 1994). Ngoài ra, kỹ thuật NMR có thể cung cấp nhiều thông tin về trật tự nguyên tử sắp xếp trong phân tử và trong thực tế có thể được sử dụng để xác định các liên kết hóa học và khoảng cách giữa các nguyên tử cụ thể (Sun et al., 2012).

Bên cạnh những phương pháp thực nghiệm, các kỹ thuật tính toán ngày càng được sử dụng rộng rãi để nghiên cứu sâu hơn các tính chất của các hạt nanocluster và sự tương tác của chúng với các phân tử sinh học (Petty et al., 2014; Sharma et al., 2012). Nhìn chung, những nghiên cứu này có thể được thực hiện ở nhiều mức lý thuyết khác nhau. Nếu chúng ta cần thông tin chính xác về cấu trúc, năng lượng và quang phổ thì tính toán hóa học lượng tử sẽ là sự lựa chọn thích hợp nhất. Trong trường hợp không có sự phá vỡ liên kết cũ và hình thành liên kết mới, phương pháp AA (All Atom) có thể được sử dụng. Nếu tương tác tĩnh điện là đóng góp chủ yếu ta có thể dựa vào mô hình $\mathrm{CG}$ (coarse grain models). Các mức mô phỏng thấp hơn (như mô hình liên tục) sẽ phù hợp đối với các hệ có kích thước lớn, thời gian tính toán dài. Trong nghiên cứu này, các phép tính DFT (density functional theory - Lý thuyết phiếm hàm mật độ) sẽ được sử dụng để khảo sát các đặc tính hấp phụ/giải hấp phụ và phản ứng điện tử của quá trình gắn kết rotigotine (ROT) lên bề mặt nanocluster vàng, sử dụng $\mathrm{Au}_{6}$ làm mô hình phản ứng.<smiles>CCCN(CCc1cccs1)[C@H]1CCc2c(O)cccc2C1</smiles>

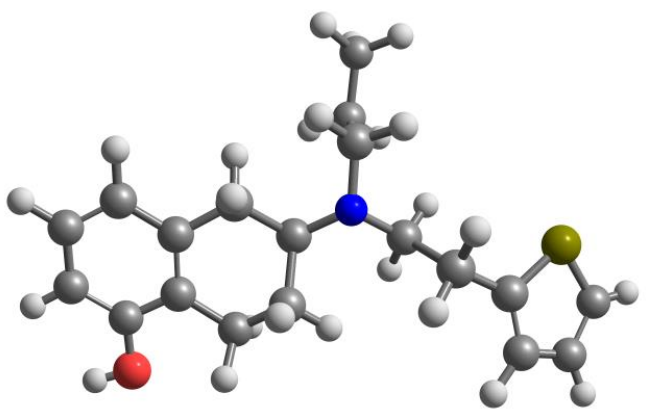

Hình 1. Cấu trúc hóa học và hình học tối ưu của rotigotine (ROT)

Rotigotine (Hình 1), còn có tên thương mại Neupro, là một chất chủ vận dopamine thuộc nhóm thuốc không chứa ergoline thường được dùng để điều trị bệnh Parkinson và hội chứng chân không yên (Chen et al., 2009). Tuy nhiên, việc sử dụng rotigotine có thể gây ra nhiều tác dụng phụ không mong muốn như táo bón, rối loạn vận động, buồn nôn, chóng mặt, mất ngủ, ảo giác (Kulisevsky \& Pagonabarraga, 2010). Các biến chứng nghiêm trọng hơn bao gồm rối loạn tâm thần và rối loạn kiểm soát xung động (Wingo et al., 2009). Vì thế, nhiều nghiên cứu đã được thực hiện để tìm ra phương pháp thích hợp nhằm giảm liều thuốc sử dụng và từ đó có thể hạn chế các phản ứng phụ của thuốc (Bi et al., 2016). Ngoài ra, việc phát triển các thiết bị cảm biến đơn giản để phát hiện nhanh chóng, chọn lọc loại thuốc này cũng là chủ đề rất đáng được quan tâm. Việc cố định các hợp chất hữu cơ và phân tử sinh học trên bề mặt vàng là nền tảng của nhiều ứng dụng trong dẫn truyền thuốc và cảm biến sinh 
học. Kết quả nghiên cứu cung cấp những hiểu biết sâu hơn về quá trình chức năng hóa các nanocluster kim loại và dự đoán khả năng ứng dụng của chúng trong việc thiết kế các hệ dẫn truyền thuốc nhắm mục tiêu, hỗ trợ thiết kế các vật liệu nano mới với hiệu quả vượt trội hơn.

\section{PHƯƠNG PHÁP TÍNH TOÁN}

Tất cả các tính toán được thực hiện bằng chương trình Gaussian 09 (Frisch et al., 2016). Cấu trúc được tối ưu hóa hoàn toàn, không có bất kỳ ràng buộc đối xứng hoặc hình học nào, trong khuôn khổ lý thuyết DFT với phiếm hàm PBE. Bộ cơ sở ccpVTZ-PP (Peterson \& Puzzarini, 2005) với thế năng lõi hiệu dụng (effective core potential) được áp dụng cho nguyên tố vàng, trong khi bộ cơ sở đầy đủ electron cc-pVTZ được sử dụng cho các nguyên tố phi kim. Cấu trúc ban đầu của phức hợp Rotigotine $-\mathrm{Au}_{6}\left(\mathrm{Au}_{6} \cdot \mathrm{ROT}\right)$ được xây dựng bằng cách gắn phân tử thuốc vào dạng bền nhất của $\mathrm{Au}_{6}$ (Nhat et al., 2017), thông qua những vị trí giàu electron, cụ thể là $\mathrm{S}, \mathrm{N}$ và $\mathrm{O}$. Tần số dao động điều hòa cũng được tính tại cùng mức lý thuyết để xác định cấu trúc thu được là những cực tiểu địa phương (local minima) trên bề mặt thế năng và năng lượng dao động điểm không ZPE (zero-point vibrational energy). Biến thiên năng lượng tự do được tính dựa vào biểu thức:

$$
\Delta G^{0}(298 K)=\Delta E+\triangle Z P E+\triangle T C G(1)
$$

Trong đó $\Delta \mathrm{E}$ là chênh lệch năng lượng electron ở $0 \mathrm{~K} ; \Delta \mathrm{ZPE}$ là chênh lệch năng lượng dao động; $\Delta \mathrm{TCG}$ là sự hiệu chỉnh năng lượng Gibbs từ 0 lên $298 \mathrm{~K}$.

Năng lượng liên kết $\mathrm{E}_{\mathrm{b}}$ của các phức hợp $\mathrm{Au}_{\mathrm{N}} \cdot \mathrm{ROT}$ được xác định như sau:

$$
E_{b}=\left(E_{\mathrm{Au}_{6}}+E_{\mathrm{ROT}}\right)-E_{\mathrm{Au}_{6} \cdot \mathrm{ROT}}
$$

Trong đó $E_{X}$ là năng lượng tối ưu của cấu tử $X$. Giá trị $\mathrm{E}_{\mathrm{b}}$ càng dương, ái lực với cluster vàng càng lớn, sự tương tác càng dễ xảy ra. Sự ảnh hưởng của dung môi (nước) được mô phỏng theo mô hình IEFPCM (Integral Equation Formalism-Polarizable Continuum Model) (Tomasi et al., 2005) có sã̃n trong chương trình Gaussian 09. Sự ảnh hưởng qua lại giữa cấu tử hấp phụ và bị hấp phụ được khảo sát thông qua các tính chất điện tử như năng lượng $\mathrm{HOMO}$, LUMO và năng lượng vùng cấm.

\section{KẾT QUẢ VÀ THẢO LUẬN}

\subsection{Tối ưu hóa cấu trúc}

Ở trạng thái cơ bản, $\mathrm{Au}_{6}$ có cấu trúc phẳng (Hình 2), được tạo nên từ 4 tam giác với 9 liên kết $\mathrm{Au}-\mathrm{Au}$ (Nhat et al., 2017). Rotigotine có thể tương tác với $\mathrm{Au}_{6}$ thông qua các trung tâm giàu điện tử $\mathrm{S}, \mathrm{N}$, hoặc $\mathrm{O}$. Các nguyên tử này chứa cặp electron tự do sằn sàng tạo liên kết với các orbital $5 d$ và $6 s$ của $\mathrm{Au}$. Tiểu phân $\mathrm{Au}_{6}$ còn có thể đóng vai trò là chất nhận proton để hình thành các liên kết $\mathrm{H}$ phi truyền thống $\mathrm{Au}^{\cdots} \cdot \mathrm{H}-\mathrm{O}$, trong đó điện tích được dịch chuyển từ cặp không liên kết của vàng và orbital phản liên kết $\sigma^{*}(\mathrm{NH})$ (Pakiari \& Jamshidi, 2007). Những tương tác này là những yếu tố bổ sung giúp ổn định phức hợp $\mathrm{Au}_{6} \cdot \mathrm{ROT}$ được tạo ra. Phân tích điện tích NBO trong $\mathrm{Au}_{6}$ cho thấy các nguyên tử $\mathrm{Au}$ nằm ở góc phù hợp hơn cho các tác kích nucleophile vì chúng tích điện dương.

Trong pha khí, có tất cả 3 cấu trúc bền được tìm thấy cho $\mathrm{Au}_{6} \cdot \mathrm{ROT}$. Hình dạng và năng lượng tương đối của chúng được thể hiện trên Hình 2. Các cấu trúc này được ký hiệu là $\mathrm{Au}_{6} \cdot \mathrm{ROT}_{-} \mathrm{X}$ với $\mathrm{X}=1,2 \ldots$ tương ứng với năng lượng tương đối tăng dần. Vị trí liên kết ưa thích nhất của ROT được xác định là nguyên tử $\mathrm{N}$, tạo ra dạng bền nhất $\mathrm{Au}_{6} \cdot \mathrm{ROT}_{-} 1$ với năng lượng liên kết là $-18,6 \mathrm{kcal} / \mathrm{mol}$. $\mathrm{Au}_{6} \cdot \mathrm{ROT} \_1$ còn được ổn định nhờ liên kết bổ sung của vòng thiophene với các nguyên tử $\mathrm{Au}$. Hơn nữa, phù hợp với phân tích NBO được đề cập ở trên, sự phối trí thông qua nguyên tử Au ở góc, tích điện dương có lợi hơn về mặt năng lượng cho sự hấp phụ ROT. Đồng phân tiếp theo, $\mathrm{Au}_{6} \cdot \mathrm{ROT} 2$ trên Hình 2 , thu được bằng cách gắn kết $\mathrm{ROT}$ với $\mathrm{Au}_{6}$ thông qua nguyên tử $\mathrm{S}$ của vòng thiophene. Tại mức lý thuyết PBE/cc-pVTZ/cc-pVTZ-PP, $\mathrm{Au}_{6} \cdot \mathrm{ROT} 2$ có năng lượng cao hơn $\mathrm{Au}_{6} \cdot \mathrm{ROT} \_1 \sim 2,5 \mathrm{kcal} / \mathrm{mol}$. Cấu trúc còn lại $\mathrm{Au}_{6} \cdot \mathrm{ROT} 3$ được xây dựng bằng cách gắn trực tiếp nguyên tử $\mathrm{O}$ vào $\mathrm{Au}_{6}$, được xác định nằm trên $\mathrm{Au}_{6} \cdot \mathrm{ROT} \_1 \sim 21 \mathrm{kcal} / \mathrm{mol}$. Lưu ý rằng tất cả các kết quả được đề cập ở trên được tính trong pha khí. Để khảo sát sự ảnh hưởng của môi trường sinh học đến hoạt tính của các phức hợp, chúng tôi thực hiện các tính toán trong dung dịch nước sử dụng mô hình IEF-PCM. Nhìn chung, sản phẩm với liên kết $\mathrm{N}-\mathrm{Au}_{6}$ vẫn là dạng ổn định nhất trong dung môi nước. 


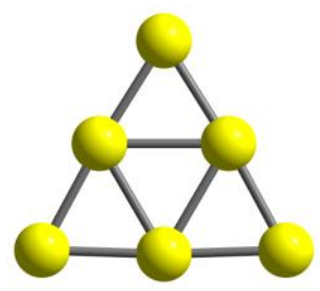

$\mathrm{Au}_{6}$

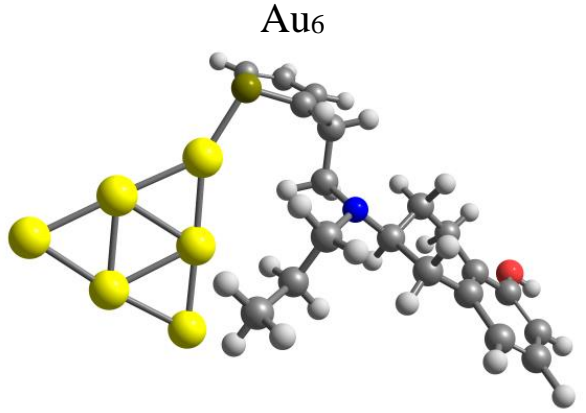

Au6·ROT_2 (2,53)

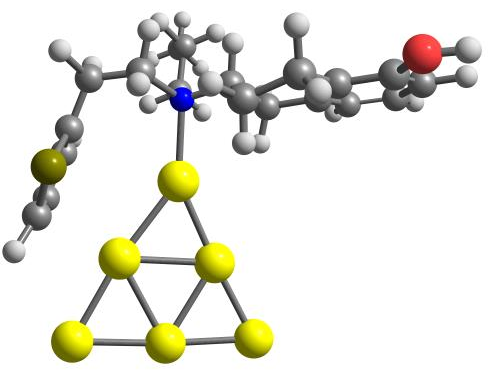

Au6:ROT_1 $(0,00)$

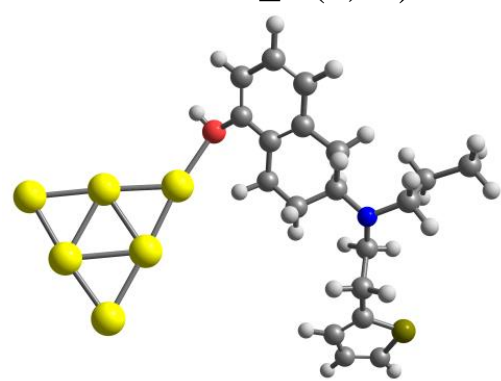

Au6·ROT_3 $(20,8)$

Hình 2. Cấu trúc tối ưu của $A u_{6}$ và các phức $A u_{6} \cdot R O T$ sinh ra từ sự gắn kết $A_{6} u_{6}$ với rotigotine. Giá trị trong ngoặc đơn là năng lượng tương đối $(\mathrm{kcal} / \mathrm{mol})$ so với dạng bển nhất Au6·ROT_1, tính tại mức lý thuyết PBE/cc-pVTZ/cc-pVTZ-PP

\subsection{Các tính chất về năng lượng, điện tử}

Để đánh giá độ bền nhiệt động của các phức hợp $\mathrm{Au}_{6} \cdot \mathrm{ROT}$, chúng tôi khảo sát năng lượng liên kết, biến thiên enthalpy và năng lượng Gibbs. Sự ảnh hưởng của dung môi nước lên độ bền của chúng cũng được xem xét. Kết quả tính toán được trình bày trong Bảng 1.

Trong pha khí, năng lượng liên kết $\left(\mathrm{E}_{\mathrm{b}}\right)$ giữa $\mathrm{Au}_{6}$ và $\mathrm{ROT}$ thay đổi từ $-18,6\left(\mathrm{Au}_{6} \cdot \mathrm{ROT} \_1\right)$ dến $-7,70$ $\mathrm{kcal} / \mathrm{mol} \quad\left(\mathrm{Au}_{6} \cdot \mathrm{ROT}_{-} 3\right)$. Biến thiên enthalpy $\left(\Delta \mathrm{H}^{298}\right)$ tương ứng nằm trong khoảng từ $-17,5$ đến $-6,69 \mathrm{kcal} / \mathrm{mol}$. Tuy nhiên, biến thiên năng lượng
Gibbs của các phản ứng này kém âm hơn rất nhiều. Phức bền nhất $\mathrm{Au}_{6} \cdot \mathrm{ROT} \_1$ có giá trị $\Delta \mathrm{G}^{298}=-2,33$ $\mathrm{kcal} / \mathrm{mol}$, so với giá trị $\Delta \mathrm{H}^{298}$ tương ứng là $-17,5$ $\mathrm{kcal} / \mathrm{mol}$. Điều này được giải thích là do entropy của các quá trình hấp phụ có xu hướng giảm. Trong dung môi nước, các giá trị $\mathrm{E}_{\mathrm{b}}, \Delta \mathrm{H}^{298}$ và $\Delta \mathrm{G}^{298}$ nhìn chung vẫn thể hiện xu hướng giống như trong pha khí. Ví dụ, năng lượng liên kết, biến thiên enthalpy và năng lượng Gibbs của $\mathrm{Au}_{6} \cdot \mathrm{ROT}_{-} 1$ trong nước là $-18,9 ;-17,0$ và $-4,18 \mathrm{kcal} / \mathrm{mol}$, so với các giá trị tương ứng trong pha khí là $-18,6 ;-17,5$ và $-2,33$ $\mathrm{kcal} / \mathrm{mol}$.

Bảng 1. Năng lượng liên kết $E_{b}$, biến thiên enthalpy $\Delta H^{298}$ và năng lượng Gibbs $\Delta G^{298}(\mathrm{kcal} / \mathrm{mol})$ của sự hấp phụ ROT lên $\mathrm{Au}_{6}$ cluster, cùng với độ dài liên kết $\mathrm{Au}-\mathrm{X}(\mathrm{A})$ trong $\mathrm{Au}_{6} \cdot \mathrm{ROT}$

\begin{tabular}{|c|c|c|c|c|c|c|c|}
\hline \multirow{2}{*}{ Cấu tử } & $\mathbf{E}_{\mathrm{b}}$ & $\Delta \mathbf{H}^{298}$ & $\Delta \mathbf{G}^{298}$ & $\mathbf{E}_{\mathbf{b}}$ & $\Delta \mathbf{H}^{298}$ & $\Delta \mathbf{G}^{298}$ & \multirow{2}{*}{$\begin{array}{r}\boldsymbol{r}_{\mathrm{Au}-\mathrm{X}} \\
(\mathbf{X}=\mathbf{N}, \mathbf{S}, \mathbf{O})\end{array}$} \\
\hline & \multicolumn{3}{|c|}{ Trong pha khí } & \multicolumn{3}{|c|}{ Trong nước } & \\
\hline $\mathrm{Au}_{6} \cdot \mathrm{ROT}_{-} 1$ & $-18,6$ & $-17,5$ & $-2,33$ & $-18,9$ & $-17,0$ & $-4,18$ & 2,33 \\
\hline $\mathrm{Au}_{6} \cdot \mathrm{ROT} \_2$ & $-16,0$ & $-14,9$ & $-4,86$ & $-14,3$ & $-13,4$ & $-2,05$ & 2,47 \\
\hline $\mathrm{Au}_{6} \cdot \mathrm{ROT} \_3$ & $-7,70$ & $-6,69$ & 4,64 & $-5,75$ & $-4,70$ & 5,48 & 2,50 \\
\hline
\end{tabular}

Khi tiếp xúc với ánh sáng hoặc bị kích thích bởi nhiệt, ROT có thể trải qua quá trình giải hấp phụ. Để hiểu sâu hơn về vấn đề này, chúng tôi tính toán thời gian hồi phục (recovery time) của quá trình hấp phụ các phân tử ROT lên bề mặt $\mathrm{Au}_{6}$. Theo thuyết trạng thái chuyển tiếp (transition-state theory), năng lượng liên kết càng mạnh thời gian hồi phục càng dài (Peng et al., 2004). Theo đó, giữa thời gian hồi phục $\tau$ và năng lượng liên kết $\mathrm{E}_{\mathrm{b}}$ liên hệ với nhau qua biểu thức:

$$
\tau=\frac{1}{v} \mathrm{e}^{\mathrm{E}_{\mathbf{b}} / k \mathrm{~T}}
$$


Trong đó, $\mathrm{T}$ là nhiệt độ của hệ; $k$ là hằng số Boltzman; $v$ là tần số thử. Với năng lượng liên kết $\mathrm{E}_{\mathrm{b}} \approx-18,6 \mathrm{kcal} / \mathrm{mol}$, thời gian hồi phục của $\mathrm{Au}_{6} \cdot \mathrm{ROT} \_1$ trong pha khí là 0,1 giây nếu sử dụng ánh sáng có bước sóng $\lambda=700 \mathrm{~nm}$, tại nhiệt độ $\mathrm{T}=$ $298 \mathrm{~K}$. Trong nước, năng lượng liên kết $\mathrm{E}_{\mathrm{b}} \approx-18,9$ $\mathrm{kcal} / \mathrm{mol}$ và thời gian hồi phục là khoảng 0,2 giây (đối với $\mathrm{Au}_{6} \cdot \mathrm{ROT}_{-}{ }_{1}$ ). Do đó, cluster vàng $\mathrm{Au}_{6}$ là vật liệu rất tiềm năng để phát triển thiết bị cảm biến trong phát hiện chọn lọc ROT.

Ngoài ra, để đánh giá độ nhạy của $\mathrm{Au}_{6}$ với sự hiện diện của các phân tử ROT, chúng tôi khảo sát sự thay đổi của năng lượng vùng cấm $\left(\Delta \mathrm{E}_{\mathrm{g}}\right)$. Chỉ số lượng tử này được xác định như sau:

$$
\Delta E_{g}=\frac{\left|E_{g_{2}}-E_{g_{1}}\right|}{E_{g_{1}}} \times 100 \%
$$

Trong đó $\mathrm{E}_{\mathrm{g}_{1}}$ và $\mathrm{E}_{\mathrm{g}_{2}}$ là năng lượng vùng cấm (chênh lệch năng lượng HOMO - LUMO) của cluster $\mathrm{Au}_{6}$ và của các phức hợp $\mathrm{Au}_{6} \cdot \mathrm{ROT}$. Các mức năng lượng biên ( $\left.\mathrm{E}_{\mathrm{HOMO}}, \mathrm{E}_{\mathrm{LUMO}}\right)$ và năng lượng vùng cấm $\left(\mathrm{E}_{\mathrm{g}}\right)$ tính tại mức lý thuyết $\mathrm{PBE} / \mathrm{cc}-\mathrm{pVTZ}$ /cc-pVTZ-PP được liệt kê trong Bảng 2. Giá trị $\mathrm{E}_{\mathrm{g}}$ thực nghiệm của $\mathrm{Au}_{6}$ được xác định từ phổ quang electron (photoelectron spectroscopy) là $2,30 \mathrm{eV}$ (Zhai et al., 2005), so với kết quả tính toán bằng phiếm hàm $\mathrm{PBE}$ là $2,09 \mathrm{eV}$ trong pha khí và $2,28 \mathrm{eV}$ trong nước. Năng lượng vùng cấm $\mathrm{E}_{\mathrm{g}}$ là một chỉ số quan trọng để xác định hoạt tính động học của các vật liệu (Hadipour et al., 2015). Sự thay đổi năng lượng vùng cấm $\left(\Delta \mathrm{E}_{\mathrm{g}}\right)$ thể hiện độ nhạy của chất hấp phụ đối với chất bị hấp phụ. Trong dung môi nước, sự hấp phụ các phân tử ROT đã làm thay đổi đáng kể năng lượng vùng cấm của $\mathrm{Au}_{6}$. Ví dụ, khi hình thành $\mathrm{Au}_{6} \cdot \mathrm{ROT}$ 1, giá trị $\mathrm{E}_{\mathrm{g}}$ của $\mathrm{Au}_{6}$ giảm từ 2,28 $\mathrm{eV}$ còn $1,77 \mathrm{eV}$, tương ứng với $\Delta \mathrm{E}_{\mathrm{g}} \approx 22,4 \%$ (Bảng 2). Sự suy giảm năng lượng vùng cấm $E_{g}$ làm gia tăng khả năng dẫn điện của $\mathrm{Au}_{6}$, gây ra tín hiệu điện và nhờ đó có thể giúp phát hiện ROT.

Bảng 2. Năng lượng ( $\mathrm{eV})$ của các orbital biên (HOMO, LUMO), năng lượng vùng cấm $\mathrm{E}_{\mathrm{g}}$, sự thay đổi năng lượng vùng cấm $\Delta \mathrm{E}_{\mathrm{g}}(\%)$ và thời gian hồi phục $\tau$ (giây) của $\mathrm{Au}_{6}$

\begin{tabular}{|c|c|c|c|c|c|c|c|c|}
\hline \multirow{2}{*}{ Cấu tử } & Еномо & ELUMo & $\mathbf{E}_{\mathrm{g}}$ & $\Delta \mathbf{E}_{\mathrm{g}}$ & HOMO & LUMO & $\mathbf{E}_{\mathrm{g}}$ & $\Delta \mathrm{E}_{\mathrm{g}}$ \\
\hline & \multicolumn{4}{|c|}{ Trong pha khí } & \multicolumn{4}{|c|}{ Trong nước } \\
\hline$\overline{\mathrm{Au}_{6}}$ & $-5,94$ & $-3,86$ & 2,09 & - & $-5,36$ & $-3,08$ & 2,28 & \\
\hline $\mathrm{Au}_{6} \cdot \mathrm{ROT}_{-} 1$ & $-4,59$ & $-2,88$ & 1,71 & 17,8 & $-4,73$ & $-2,96$ & 1,77 & 22,4 \\
\hline
\end{tabular}

\subsection{Sự phóng thích thuốc}

Quá trình phóng thích thuốc từ chất mang trong các tế bào đích là một giai đoạn quan trọng trong dẫn truyền thuốc. Thuốc có thể được giải phóng từ chất mang bởi kích thích bên ngoài như ánh sáng hoặc kích thích bên trong được kiểm soát bởi yếu tố sinh học như pH hoặc glutathione (Ghosh et al., 2008). Do acid lactic được sản xuất quá nhiều, các tế bào khối u thường có độ $\mathrm{pH}$ thấp hơn (dưới 6) so với máu ( $\mathrm{pH} \approx 7,35-7,45)$ (Swietach et al., 2014). Chính vì vậy, nghiên cứu xem xét độ bền của các phức hợp $\mathrm{Au}_{6}$ ROT với sự hiện diện và vắng mặt của proton. Trong môi trường acid, các trung tâm ái nhân của thuốc đều có thể bị tấn công bởi các proton, nhưng chúng ít ảnh hưởng đến quá trình phóng thích thuốc (Hazrati et al., 2017). Do đó, chúng tôi chỉ khảo sát sự ảnh hưởng của các ion hydrogen lên độ bền liên kết do sự proton hóa nguyên tử $\mathrm{N}$ và thực hiện tối ưu hóa cho phức hợp tương ứng $\mathrm{Au}_{6} \cdot \mathrm{ROTH}^{+}$.

Trong môi trường acid, tương tác giữa ROT và cluster vàng trở nên mong manh hơn rất nhiều. Bản chất của tương tác được quyết định bởi bởi liên kết H như trong Hình 3, thay vì cộng hóa trị như trong $\mathrm{Au}_{6} \cdot \mathrm{ROT}$. Năng lượng liên kết của ROT với $\mathrm{Au}_{6}$ giảm đáng kể, chỉ còn $-2,3 \mathrm{kcal} / \mathrm{mol}$ so với các giá trị $-19 \mathrm{kcal} / \mathrm{mol}$ trong môi trường trung tính. Do đó, với sự hiện diện của ion $\mathrm{H}^{+}$, sự gắn kết giữa $\mathrm{ROT}$ với chất mang dễ dàng bị phá vỡ và nhanh chóng được phóng thích khỏi bề mặt vàng.

Một yếu tố quan trong khác có thể gây ra sự phóng thích thuốc là sự kích thích bên trong liên quan đến các amino acid trong các protein. Các hợp phần chứa $\mathrm{S}$ như cysteine và methionine được dự đoán là những vị trí liên kết được ưa thích đối với kim loại quý (Eckhardt et al., 2013; Le Guével et al., 2011). Hằng số acid của cysteine là $\mathrm{p} K_{1}=1,7$ và $\mathrm{p} K_{2}$ = 8,3 (O'Neil, 2013). Như vậy, trong các hệ sinh học hoặc trong dung dịch nước, cysteine chủ yếu tồn tại dưới dạng anion như biểu diễn trên Hình 3 . Để đánh giá khả năng phóng thích thuốc từ bề mặt vàng, chúng tôi xem xét quá trình trao đổi phối tử theo phương trình sau:

$$
\mathrm{Au}_{6} \cdot \mathrm{ROT}_{(\mathrm{aq})}+\mathrm{Cys}\left(-\mathrm{H}^{+}\right)_{(\mathrm{aq})} \rightarrow \mathrm{Au}_{6} \cdot \mathrm{Cys}\left(-\mathrm{H}^{+}\right)_{(\mathrm{aq})}
$$$$
+\mathrm{ROT}_{(\mathrm{aq})}
$$ 

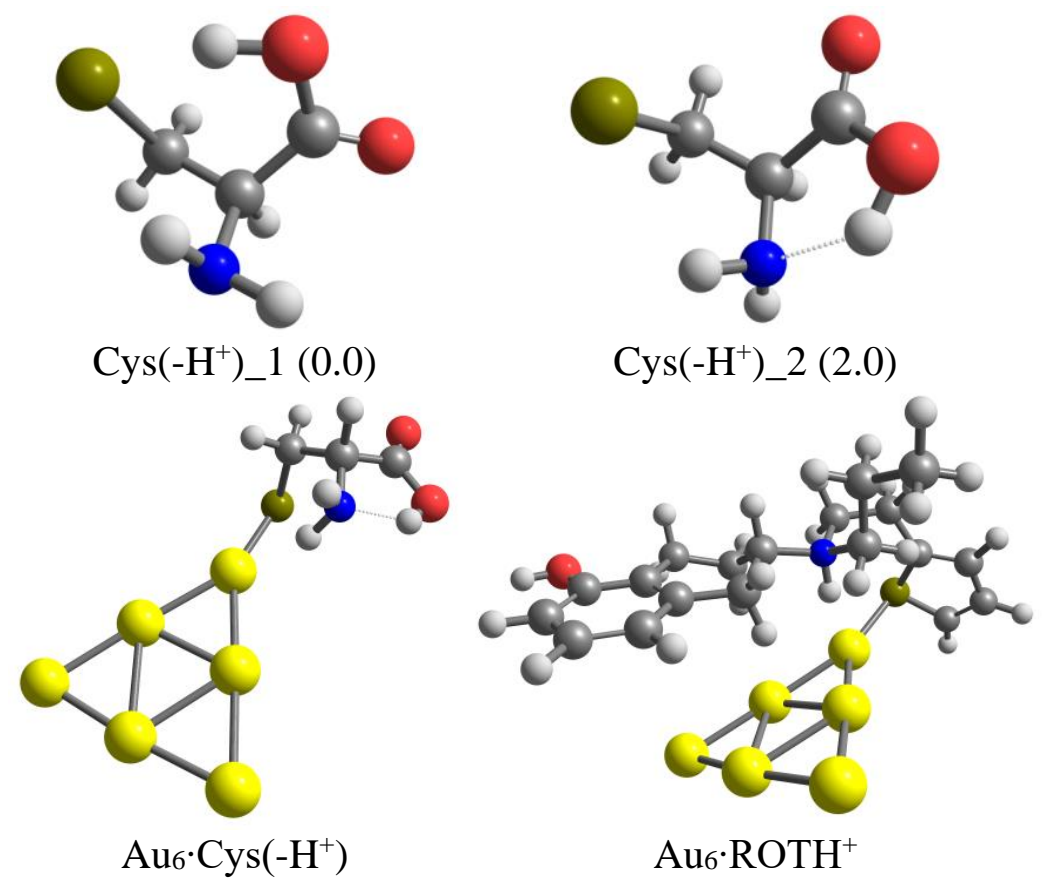

\section{Hình 3. Cấu trúc tối ưu của cysteine trong nước, phức hợp của nó với Aub và cấu trúc tối ưu của $\mathrm{Au}_{6} \cdot \mathbf{R O T H}^{+}$}

Cấu trúc bền nhất của $\mathrm{Au}_{6}$ với cysteine bị tách proton, Cys $\left(-\mathrm{H}^{+}\right)$, được thể hiện trên Hình 3. Nghiên cứu gần đây về sự tương tác của $\mathrm{Au}_{6}$ với cystein cho thấy cysteine liên kết với cluster vàng thông qua nguyên tử $\mathrm{S}$ của nhóm thiol trong pha khí và nhóm thiolate trong nước (Nhat et al., 2020). Trong dung dịch acid, năng lượng liên kết cysteine- $\mathrm{Au}_{6}$ được xác định là khoảng $-20 \mathrm{kcal} / \mathrm{mol}$. Giá trị này tăng lên rất nhiều trong môi trường trung tính, cụ thể là $-39 \mathrm{kcal} / \mathrm{mol}$. Trong nước, năng lượng liên kết của rotigitine với $\mathrm{Au}_{6}$ là $-19 \mathrm{kcal} / \mathrm{mol}$. Vì thế, có thể dự đoán rằng $\mathrm{Au}_{6}$ tương tác với cystein mạnh hơn nhiều so với rotigitine. Như vây, sự phóng thích thuốc từ bề mặt vàng trong các tế bào đích chắc chắn sẽ xảy ra do sự tương tác với các protein. Thật vậy, năng lượng Gibbs cho phản ứng trao đổi phối tử được tính là khoảng $-10 \mathrm{kcal} / \mathrm{mol}$ đối với rotigotine. Biến thiên năng lượng tự do âm cho thấy đây là quá trình tự diễn biến.

\section{KẾT LUẬN}

Trong nghiên cứu này, cơ chế hấp phụ/giải hấp phụ của phân tử thuốc rotigitine trên bề mặt $\mathrm{Au}_{6}$ được mô tả một cách hệ thống bằng lý thuyết phiếm hàm mật độ DFT. Phiếm hàm GGA thuần túy (PBE) được sử dụng kết với với bộ cơ sở cc-pVTZ-PP cho vàng và $\mathrm{cc}-\mathrm{pVTZ}$ cho các phi kim. Cấu trúc, các tham số nhiệt động và tính chất điện tử của phức hợp tạo thành được xác định và phân tích chi tiết. Sự ảnh hưởng của nước lên khả năng tương tác được khảo sát bằng mô hình IEF-PCM.

Kết quả tính toán cho thấy nguyên tử Au chủ yếu liên kết với rotigotine thông qua nguyên tử $N$. Năng lượng liên kết vào khoảng $-18,6 \mathrm{kcal} / \mathrm{mol}$ trong pha khí và $-18,9 \mathrm{kcal} / \mathrm{mol}$ trong môi trường nước. Quá trình hấp phụ có biến thiên năng lượng tự do Gibbs âm nên được dự đoán là có thể tự diễn biến. Nhìn chung, cấu trúc nguyên tử của cả cluster vàng và phân tử thuốc đều thay đổi không đáng kể do sự tạo phức. Tuy nhiên, năng lượng vùng cấm của $\mathrm{Au}_{6}$ giảm đáng kể trong phức hợp $\mathrm{Au}_{6} \cdot \mathrm{ROT}$. So với $\mathrm{Au}_{6}$ tự do, năng lượng vùng cấm $\mathrm{E}_{\mathrm{g}}$ của $\mathrm{Au}_{6}$. ROT giảm đến $18 \%$ trong pha khí và $22 \%$ và trong nước. Sự thay đổi này có thể được chuyển hóa thành tín hiệu điện giúp phát hiện chọn lọc ROT. Các kết quả tính toán này cung cấp cho chúng ta những hiểu biết sâu sắc hơn về các yếu tố thúc đẩy sự gắn kết các phân tử thuốc/phân tử sinh học lên bề mặt các hạt nano vàng và khả năng ứng dụng của các vật liệu nano vàng để thiết kế hệ thống dẫn truyền thuốc nhắm mục tiêu, cảm biến sinh học chọn lọc cực nhỏ với hiệu quả vượt trội.

\section{LỜI CẢM ƠN}

Nghiên cứu này được tài trợ bởi Bộ Giáo dục và Đào tạo với mã số đề tài B2020-TCT-11; và bởi Dự án Nâng cấp Trường Đại học Cần Thơ VN14-P6 bằng nguồn vốn vay $\mathrm{ODA}$ từ chính phủ Nhật Bản. 
Nhóm tác giả xin chân thành cảm ơn Trung tâm Tính toán Đại học Jackson States, Hoa Kỳ đã cho phép sử dụng sức máy để thực hiện những tính toán trong nghiên cứu này.

\section{TÀI LIỆU THAM KHẢO}

Achar, S., \& Puddephatt, R. J. (1994). Organoplatinum dendrimers formed by oxidative addition. Angewandte Chemie International Edition, 33(8), 847-849.

Bi, C., Wang, A., Chu, Y., Liu, S., Mu, H., Liu, W., . . Li, Y. (2016). Intranasal delivery of rotigotine to the brain with lactoferrin-modified PEGPLGA nanoparticles for Parkinson's disease treatment. International journal of nanomedicine, 11, 6547-6559.

Brar, S. K., \& Verma, M. (2011). Measurement of nanoparticles by light-scattering techniques. Trends in Analytical Chemistry, 30(1), 4-17.

Chah, S., Hammond, M. R., \& Zare, R. N. (2005). Gold nanoparticles as a colorimetric sensor for protein conformational changes. Chemistry \& Biology, 12(3), 323-328. doi:10.1016/j.chembiol.2005.01.013

Chen, J. J., Swope, D. M., Dashtipour, K., \& Lyons, K. E. (2009). Transdermal rotigotine: A clinically innovative dopamine-receptor agonist for the management of Parkinson's disease. Pharmacotherapy: The journal of human pharmacology and drug therapy, 29(12), 1452-1467.

Choi, S., Dickson, R. M., \& Yu, J. (2012). Developing luminescent silver nanodots for biological applications. Chemical Society Reviews, 41(5), 1867-1891. doi:10.1039/c1cs15226b

Eckhardt, S., Brunetto, P. S., Gagnon, J., Priebe, M., Giese, B., \& Fromm, K. M. (2013). Nanobio silver: its interactions with peptides and bacteria, and its uses in medicine. Chemical Reviews, 113(7), 4708.

Fenwick, O., Coutiño-Gonzalez, E., Grandjean, D., Baekelant, W., Richard, F., Bonacchi, S., . . . Samorì, P. (2016). Tuning the energetics and tailoring the optical properties of silver clusters confined in zeolites. Nature Materials, 15, 1017.

Frisch, M. J., Trucks, G. W., Schlegel, H. B., Scuseria, G. E., Robb, M. A., Cheeseman, J. R., . . . Fox, D. J. (2016). Gaussian 16 Rev. B.01. Wallingford, CT.

Ghosh, P., Han, G., De, M., Kim, C. K., \& Rotello, V. M. (2008). Gold nanoparticles in delivery applications. Advanced Drug Delivery Reviews, 60(11), 1307.

Gwinn, E., Schultz, D., Copp, S. M., \& Swasey, S. (2015). DNA-protected silver clusters for nanophotonics. Nanomaterials (Basel), 5(1), 180-207. doi:10.3390/nano5010180

Hadipour, N. L., Ahmadi Peyghan, A., \& Soleymanabadi, H. (2015). Theoretical study on the Al-doped $\mathrm{ZnO}$ nanoclusters for $\mathrm{CO}$ chemical sensors. Journal of Physical Chemistry C, 119(11), 6398.

Hazrati, M. K., Bagheri, Z., \& Bodaghi, A. (2017). Application of $\mathrm{C}_{30} \mathrm{~B}_{15} \mathrm{~N}_{15}$ heterofullerene in the isoniazid drug delivery: DFT studies. Physica E: Low-dimensional Systems and Nanostructures, 89, 72-76.

Jain, P. K., Lee, K. S., El-Sayed, I. H., \& El-Sayed, M. A. (2006). Calculated absorption and scattering properties of gold nanoparticles of different size, shape, and composition: applications in biological imaging and biomedicine. Journal of Physical Chemistry B, 110(14), 7238-7248. doi:10.1021/jp057170o

Kam, N. W. S., Liu, Z., \& Dai, H. (2005). Functionalization of carbon nanotubes via cleavable disulfide bonds for efficient intracellular delivery of siRNA and potent gene silencing. Journal of the American Chemical Society, 127(136), 12492-12493.

Kulisevsky, J., \& Pagonabarraga, J. (2010). Tolerability and safety of ropinirole versus other dopamine agonists and levodopa in the treatment of Parkinson's disease. Drug safety, 33(2), 147-161.

Le Guével, X., Hötzer, B., Jung, G., Hollemeyer, K., Trouillet, V., \& Schneider, M. (2011). Formation of fluorescent metal $(\mathrm{Au}, \mathrm{Ag})$ nanoclusters capped in bovine serum albumin followed by fluorescence and spectroscopy. Journal of Physical Chemistry C, 115(22), 10955-10963.

Mani, V., Chikkaveeraiah, B. V., Patel, V., Gutkind, J. S., \& Rusling, J. F. (2009). Ultrasensitive immunosensor for cancer biomarker proteins using gold nanoparticle film electrodes and multienzyme-particle amplification. ACS Nano, 3(3), 585-594. doi:10.1021/nn800863w

Nhat, P. V., Nguyen, P. T. N., \& Si, N. T. (2020). A computational study of thiol-containing cysteine amino acid binding to Au6 and Aus gold clusters. Journal of Molecular Modeling, 26(3), 1.

Nhat, P. V., Si, N. T., Leszczynski, J., \& Nguyen, M. T. (2017). Another look at structure of gold clusters Aun from perspective of phenomenological shell model. Chemical Physics, 493, 140-148.

O'Neil, M. J. (2013). The Merck index: an encyclopedia of chemicals, drugs, and biologicals: RSC Publishing.

Obliosca, J. M., Liu, C., \& Yeh, H.-C. (2013). Fluorescent silver nanoclusters as DNA probes. Nanoscale, 5(18), 8443-8461. doi:10.1039/C3NR01601C 
Pakiari, A. H., \& Jamshidi, Z. (2007). Interaction of amino acids with gold and silver clusters. Journal of Physical Chemistry A, 111(20), 4391-4396.

Peng, S., Cho, K., Qi, P., \& Dai, H. (2004). Ab initio study of CNT $\mathrm{NO}_{2}$ gas sensor. Chemical Physics Letters, 387(4), 271-276.

Peterson, K. A., \& Puzzarini, C. (2005). Systematically convergent basis sets for transition metals. II. Pseudopotential-based correlation consistent basis sets for the group $11(\mathrm{Cu}, \mathrm{Ag}, \mathrm{Au})$ and $12(\mathrm{Zn}, \mathrm{Cd}, \mathrm{Hg})$ elements. Theoretical Chemistry Accounts, 114(4), 283-296.

Petty, J. T., Nicholson, D. A., Sergev, O. O., \& Graham, S. K. (2014). Near-infrared silver cluster optically signaling oligonucleotide hybridization and assembling two DNA hosts. Analytical Chemistry, 86(18), 9220-9228. doi:10.1021/ac502192w

Sharma, J., Rocha, R. C., Phipps, M. L., Yeh, H.-C., Balatsky, K. A., Vu, D. M., . . . Martinez, J. S. (2012). A DNA-templated fluorescent silver nanocluster with enhanced stability. Nanoscale, 4(14), 4107-4110. doi:10.1039/C2NR30662J

Sun, T., Guo, Q., Zhang, C., Hao, J., Xing, P., Su, J., . . . Liu, G. (2012). Self-assembled vesicles prepared from amphiphilic cyclodextrins as drug carriers. Langmuir, 28(23), 8625-8636.

Swietach, P., Vaughan-Jones, R. D., Harris, A. L., \& Hulikova, A. (2014). The chemistry, physiology and pathology of $\mathrm{pH}$ in cancer. Philosophical Transactions of the Royal Society B, 369(1638), 20130099.
Thaxton, C. S., Georganopoulou, D. G., \& Mirkin, C. A. (2006). Gold nanoparticle probes for the detection of nucleic acid targets. Clinica Chimica Acta, 363(1-2), 120-126. doi:10.1016/j.cccn.2005.05.042

Tomasi, J., Mennucci, B., \& Cammi, R. (2005). Quantum mechanical continuum solvation models. Chemical Reviews, 105(8), 2999-3094. doi:10.1021/cr9904009

Veronese, F. M., \& Pasut, G. (2005). PEGylation, successful approach to drug delivery. Drug Discovery Today, 10(21), 1451-1458.

Wang, W., Rusin, O., Xu, X., Kim, K. K., Escobedo, J. O., Fakayode, S. O., . . . Strongin, R. M. (2005). Detection of Homocysteine and Cysteine. Journal of the American Chemical Society, 127(45), 15949-15958. doi:10.1021/ja054962n

Wingo, T. S., Evatt, M., Scott, B., Freeman, A., \& Stacy, M. (2009). Impulse control disorders arising in 3 patients treated with rotigotine. Clinical neuropharmacology, 32(2), 59-62.

Xavier, P. L., Chaudhari, K., Baksi, A., \& Pradeep, T. (2012). Protein-protected luminescent noble metal quantum clusters: an emerging trend in atomic cluster nanoscience. Nano Reviews, 3, 10.3402/nano.v3403i3400.14767. doi:10.3402/nano.v3i0.14767

Zhai, H.-J., Kiran, B., Dai, B., Li, J., \& Wang, L.-S. (2005). Unique $\mathrm{CO}$ chemisorption properties of gold hexamer: $\mathrm{Au}_{6}(\mathrm{CO})_{\mathrm{n}}{ }^{-}(\mathrm{n}=0-3)$. Journal of the American Chemical Society, 127(34), 12098-12106. 